\title{
Effect of different citric acid levels and packaging materials on quality of sugar based papaya leather
}

\author{
Ankit Singh, Jaivir Singh, Neelash Chauhan, Vivak Kumar and Dinesh Kumar ${ }^{1}$ \\ Department of Agricultural Engineering and Food Technology \\ Sardar Vallabhbhai Patel University of Agriculture \& Technology, Meerut - 250110 (U.P.) \\ ${ }^{1}$ Sonalika Tractor, Shivpuri, Gwalior (MP)
}

\begin{abstract}
Experiments were conducted to investigate the effect of citric acid levels and packaging materials on physico-chemical and sensory quality of fresh and as well as stored papaya leather. The citric acid levels of $0.5 \%, 0.75 \%$ and $1.0 \%$ were used for the preparation of papaya leather. After preparation of papaya leather, the finished products were packed in two packaging materials viz. PET jars and glass jars and stored at room temperature for quality evaluation at 15, 30, 45, 60, 75 and 90 days and sensory quality evaluation at 30,60 and 90 days interval. The study revealed that the moisture content increased with citric acid levels. The TSS and vitamin $\mathrm{C}$ decreased with increase in the levels of citric acid. During storage there was a reduction in moisture content, $\mathrm{pH}$ and vitamin-C, where as TSS (total soluble solids) and optical density increases on storage. It is found that there is more loss of moisture and vitamin-C in PET jars as compared to glass jars. The organoleptic score of the leather samples in glass jars at $0.75 \%$ citric acid level was found to be higher followed by samples packed in PET jars.
\end{abstract}

Key words: TSS, acidity, $\mathrm{pH}$, leather, papaya, processing, packaging material

Papaya (Carica papaya L.) is a tropical fruit. It is originated in Central America, Mexico and Northern South America. Papaya is spherical or pear shaped fruits that can be as long as 20 inches. During the year 2009-10, India's papaya production was 3913 metric tonnes (Indian Horticulture Database 2010). The important papaya growing states are Andhra Pradesh, Tamil Nadu, Assam, Bihar, Maharashtra and Uttar Pradesh. The papaya fruits are rich source of vitamins, particularly ascorbic acid and $\beta$-carotene. Ready-to eat fruit bars are well established products and are being commercially prepared in our country. Fruit leathers from mango, papaya, pineapple, guava, juman and banana individually or in combination with different fruits (Mathur et al., 1972, and Doreyappa Gowda et al., 1995). Present investigation highglights the storage behaviour of sugar based papaya leather with different levels $(0.5 \%, 0.75 \%$ and $1.0 \%)$ of citric acid packed in different packaging materials and kept at room temperature over a period of three months.

\section{Materials and Methods}

Preparation of Papaya leather: Papaya leather was prepared from evenly ripened fruit procured in bulk from local market. Papaya were washed to potable water and remove dust, dirty particles and some bacteria's. Peeling was done manually. Pulping of papaya was done in Electric Juicer mixer. The papaya fruit pulp $(1.0 \mathrm{~kg})$ was mixed with $450 \mathrm{~g}$ of sugar, $7.25 \mathrm{~g}$ of citric acid for the preparation of papaya fruit leather with citric acid level of $0.5 \%$ after preparing papaya leather with citric acid level of $0.5 \%$ the same process is again done for the preparation of papaya leather with citric acid level of 0.75 and $1.0 \%$. The mixture was heated with continuous stirring for 5 minutes after cooking $2 \mathrm{ml}$ mixed fruit flavour is added in the blend. This blend was spread in the form of thin layer on a tray smeared with mustard oil and dried in the hot air oven at $45^{\circ} \mathrm{C}$. The dried layer was cut into rectangular leather pieces $(3.5 \times 3.5 \times 0.5 \mathrm{~cm})$ and packed individually in PET jars and glass jars and stored at room temperature for further study.

Physico-Chemical analysis: The physico-chemical analysis like moisture content (Hot air oven method), total soluble solids, $\mathrm{pH}$, optical density, and Vitamin-C for the fruit papaya leathers were determined using standard methods recommended by Ranganna (2001) as fresh and after 15, 30, 45, 60,75 and 90 days of storage period. 
Organoleptic Evaluation: The papaya leather samples were evaluated as fresh and after 30,60 and 90 days of interval by ten judges using 9-point Hedonic rating scale (Ranganna, 2001).

\section{Results and Discussion}

The data on changes in physico-chemical constituents of papaya leather as influenced by different citric acid levels and packaging materials is presented in Table 1 to 5 .

Moisture content: Moisture content of samples increased with increased in citric acid levels and moisture content of samples decreased with storage period, the reason for such trend may attributed to inversion of sucrose into monosaccharide by citric acid which is more in hygroscopic nature than the sucrose (Bhandari et al., 1997), (Bhandari and Howes, 1999) leading to relatively higher affinity for water molecules. Samples with higher level of citric acid undergone inversion of more sucrose and therefore, had higher final moisture content. From the table it is also shows that the moisture less decreases in glass jars as compared to the PET jars (Table 1)

TSS: TSS of leather samples decreased with increased in the levels of citric acid but the TSS of all leather samples prepared with different levels of citric acid increased with storage period. It is also showed that the TSS of samples packed in glass jars is higher as compared to the PET jars after storage of 90 days (Table 2).

pH: $\mathrm{pH}$ of the leather samples decreased with increased in the levels of citric acid. From the table it is also showed that the $\mathrm{pH}$ of the samples prepared with different levels of citric acid decreased during storage similar pattern of decreasing trend was reported by (Sivakumar et al. 2005) reason behind that the decreases $\mathrm{pH}$ is due to increases acidity. Among the packaging materials, the leather samples stored in PET jars had recorded higher $\mathrm{pH}$ followed by glass jars (Table 3 ).

Optical density: Optical density of the leather samples decreased with increased in the levels of citric acid. From the Table 4, it is also showed that the optical density of the samples prepared with different levels of citric acid increased during storage. This increases in non- enzymatic browning might be due to decrease in sulphur dioxide (Swaminathan, 1987; Mir and Nath, 1993), higher temperature (Meyer, 1966), as expected from Arrhenius equation (Mir and Nath, 1993) and concomitant with heat and loss of sulphur dioxide content of the product (Rao and Roy, $1980 \mathrm{~b}$ ). This might be due to reaction of sulphur dioxide with food constituents (sugars, pectin's, proteins and lipids), oxidation or due to volatilisation (Bolin and Boyle 1972; Echkoff and Okos 1986).

Vitamin-C: Vitamin-C of the leather samples decreased with increased in the levels of citric acid. From the table it is also showed that the Vitamin-C content of the samples prepared with different levels of citric acid decreased after 90 days of storage. The reason behind this is the ascorbic acid content decreased during storage due to oxidation of ascorbic acid to dehyroascorbic acid. This is due to oxidation or exposure of atmosphere oxygen while preparing the fruit leather (Fennema, 1977). The loss of Vitamin-C is more in samples packed in PET jars as compared to glass jars.

Sensory Evaluation: Table 6 shows the oragnoleptic score values for leather samples during storage. Results of sensory evaluation showed that the sensory attributes like colour, flavour, texture and taste of samples prepared with different levels of citric acid in glass jars were most acceptable up to 90 days of storage at room temperature. The results also indicated that samples prepared with citric acid level of $0.75 \%$ ranked high followed by $0.5 \%$ and $1.0 \%$ citric acid levels.

\section{Conclusion}

Physico-chemical, organoleptic changes were studied in papaya leather during storage at room temperature. Significant changes were noticed in moisture content, TSS, pH, optical density and Vitamin-C. The result indicated that the samples prepared with citric acid level of $0.75 \%$ ranked high followed by $0.5 \%$ and $1.0 \%$ citric acid levels. Among the packaging materials the samples packed in glass jars showed minimum nutrient loss and also retained maximum consumer acceptability scores.

\section{References}

1. Bhandari, B.R. and Howes, T. (1999). Implementation of glass transition for the drying and stability of dried foods. J. Food Engg. 40: 71-79. 
2. Bhandari, B.R., Datta, N. and Howes, T. (1997) Problem associated with spray drying of sugar rich foods. Drying Technol. 12 (2): 671-684.

3. Bolin, H.R. and Boyle, F.P. (1972) Effect of storage and processing on sulphur dioxide in preserved fruit.Food Product Dev. 7:82-86.

4. Doreyappa Gowda, I.N., Amba Dan and Ramanjaneya, K.H. (1995). Studies on mango fruit bar preparation. Indian FoodPacker. 49(2): 17-24.

5. Echkoff, S.R. and Okos, M.R. (1986) Kinetics of sulphite reaction in corn grain. J. Agri. Food Chem. 34: 239-245.

6. Fennema, O. (1977). Loss of vitamins in fresh and frozen food. J. food Sci. Technol. 31: 3235.

7. Mathur, N.K., Anthony Dos, S., Jayaraman, K.S. and Bhatia, B.S. (1972). Preparation of fruit bars used in combat rations, Indian Food Packer. March-April, 33-35.

8. Meyer, L.H. (1966) Food Chemistry. Reinhold Publishing Corporation, New York.
9. Mir, M.A. and Nath, N. (1993). Storage changes in fortified mango bars. J Food Sci. Technol. 30:279-282.

10. Ranganna, S. (2001). Handbook of analysis and quality control for fruit and vegetable products ( $2^{\text {nd }}$ ed). Tata McGraw Hill Pub. Co. Ltd. New Delhi.

11. Rao, V.S. and Roy, S.K. (1980b). Studies on dehydration of mango pulp II. Storage studies on dehydration of mango sheet leather. Indian Food Packer. 34:72-79.

12. Sivakumar, P. K., Malathi, D., Nallakurumban B., Kalaiselvan, A. (2005). Studies on storage stability of guava bar in different packaging materials. Bev.Food World. 32 (11). 80 - 81.

13. Swaminathan, M. (1987) Food Science, Chemistry and Experimental Foods. The Banglore Printing and Publishing Co. Ltd., Bangalore.

Table 1: Changes in Moisture content (\%) of papaya leather during storage as affected by levels of citric acid and packaging materials

\begin{tabular}{|c|c|c|c|c|c|c|}
\hline \multirow{2}{*}{$\begin{array}{c}\text { Storage } \\
\text { Period } \\
\text { (days) }\end{array}$} & \multicolumn{2}{|c|}{$\mathrm{PSC}_{0.5}$} & \multicolumn{2}{|c|}{$\mathrm{PSC}_{0.75}$} & \multicolumn{2}{|c|}{ PSC $_{1.0}$} \\
\hline & PET JAR & GLASS JAR & PET JAR & GLASS JAR & PET JAR & GLASS JAR \\
\hline Fresh & $19.00 \pm .008$ & $19.00 \pm .012$ & $19.00 \pm .014$ & $19.00 \pm .021$ & $19.00 \pm .021$ & $19.00 \pm .012$ \\
\hline 15 & $18.19 \pm .045$ & $18.80 \pm .024$ & $18.23 \pm .020$ & $18.83 \pm .028$ & $18.30 \pm .047$ & $18.95 \pm .020$ \\
\hline 30 & $18.08 \pm .008$ & $18.62 \pm .008$ & $18.12 \pm .020$ & $18.64 \pm .036$ & $18.19 \pm .036$ & $18.71 \pm .028$ \\
\hline 45 & $17.70 \pm .069$ & $17.92 \pm .065$ & $17.77 \pm .016$ & $18.02 \pm .020$ & $17.88 \pm .057$ & $18.17 \pm .012$ \\
\hline 60 & $17.32 \pm .016$ & $17.82 \pm .016$ & $17.35 \pm .024$ & $17.88 \pm .012$ & $17.43 \pm .012$ & $17.97 \pm .008$ \\
\hline 75 & $17.13 \pm .053$ & $17.31 \pm .008$ & $17.17 \pm .016$ & $17.35 \pm .028$ & $17.27 \pm .012$ & $17.55 \pm .040$ \\
\hline 90 & $16.92 \pm .021$ & $17.10 \pm .104$ & $16.99 \pm .016$ & $17.19 \pm .016$ & $17.06 \pm .028$ & $17.26 \pm .009$ \\
\hline
\end{tabular}

Table 2: Changes in total soluble solids content ( $\left.{ }^{0} \mathrm{Brix}\right)$ of papaya leather during storage as affected by levels of citric acid and packaging materials

\begin{tabular}{|c|c|c|c|c|c|c|}
\hline \multirow{2}{*}{$\begin{array}{l}\text { Storage } \\
\text { Period } \\
\text { (days) }\end{array}$} & \multicolumn{2}{|c|}{ PSC $_{\mathbf{0 . 5}}$} & \multicolumn{2}{c|}{ PSC $_{\mathbf{0 . 7 5}}$} & \multicolumn{2}{c|}{ PSC $_{\mathbf{1 . 0}}$} \\
\cline { 2 - 7 } & PET JAR & GLASS JAR & PET JAR & GLASS JAR & PET JAR & GLASS JAR \\
\hline Fresh & $64.29 \pm .042$ & $64.29 \pm .034$ & $64.23 \pm .028$ & $64.23 \pm .057$ & $64.19 \pm .062$ & $64.19 \pm .028$ \\
\hline 15 & $64.54 \pm .020$ & $64.61 \pm .016$ & $64.50 \pm .016$ & $64.56 \pm .012$ & $64.45 \pm .012$ & $64.49 \pm .065$ \\
\hline 30 & $65.31 \pm .016$ & $65.53 \pm .013$ & $65.21 \pm .025$ & $65.46 \pm .020$ & $65.15 \pm .012$ & $65.32 \pm .021$ \\
\hline 45 & $66.34 \pm .024$ & $66.57 \pm .029$ & $66.23 \pm .017$ & $66.45 \pm .033$ & $66.18 \pm .027$ & $66.40 \pm .025$ \\
\hline 60 & $67.35 \pm .025$ & $67.44 \pm .028$ & $67.25 \pm .017$ & $67.38 \pm .020$ & $67.22 \pm .032$ & $67.31 \pm .013$ \\
\hline 75 & $68.30 \pm .017$ & $68.38 \pm .020$ & $68.24 \pm .032$ & $68.33 \pm .022$ & $68.21 \pm .021$ & $68.29 \pm .032$ \\
\hline 90 & $70.07 \pm .029$ & $70.10 \pm .021$ & $69.83 \pm .013$ & $69.96 \pm .032$ & $69.61 \pm .032$ & $69.67 \pm .024$ \\
\hline
\end{tabular}


Table 3: Changes in pH content of papaya leather during storage as affected by levels of citric acid and packaging materials

\begin{tabular}{|c|c|c|c|c|c|c|}
\hline \multirow{2}{*}{$\begin{array}{c}\text { Storage } \\
\text { Period } \\
\text { (days) }\end{array}$} & \multicolumn{2}{|c|}{ PSC $_{\mathbf{0 . 5}}$} & \multicolumn{2}{c|}{ PSC $_{\mathbf{0 . 7 5}}$} & \multicolumn{2}{c|}{ PSC $_{\mathbf{1 . 0}}$} \\
\cline { 2 - 7 } & PET JAR & GLASS JAR & PET JAR & GLASS JAR & PET JAR & GLASS JAR \\
\hline Fresh & $3.80 \pm .040$ & $3.80 \pm .004$ & $3.77 \pm .012$ & $3.77 \pm .36$ & $3.73 \pm .012$ & $3.73 \pm .009$ \\
\hline 15 & $3.78 \pm .008$ & $3.79 \pm .020$ & $3.74 \pm .016$ & $3.72 \pm .012$ & $3.71 \pm .017$ & $3.67 \pm .017$ \\
\hline 30 & $3.74 \pm .016$ & $3.69 \pm .028$ & $3.71 \pm .012$ & $3.67 \pm .028$ & $3.67 \pm .016$ & $3.64 \pm .012$ \\
\hline 45 & $3.69 \pm .008$ & $3.66 \pm .012$ & $3.66 \pm .021$ & $3.64 \pm .008$ & $3.62 \pm .020$ & $3.62 \pm .013$ \\
\hline 60 & $3.63 \pm .009$ & $3.61 \pm .036$ & $3.61 \pm .012$ & $3.59 \pm .008$ & $3.60 \pm .016$ & $3.59 \pm .012$ \\
\hline 75 & $3.60 \pm .016$ & $3.56 \pm .012$ & $3.60 \pm .020$ & $3.56 \pm .020$ & $3.58 \pm .029$ & $3.55 \pm .016$ \\
\hline 90 & $3.58 \pm .016$ & $3.54 \pm .013$ & $3.56 \pm .009$ & $3.52 \pm .024$ & $3.55 \pm .041$ & $3.50 \pm .020$ \\
\hline
\end{tabular}

Table 4: Changes in optical density content of papaya leather during storage as affected by levels of citric acid and packaging materials

\begin{tabular}{|c|c|c|c|c|c|c|}
\hline \multirow{2}{*}{$\begin{array}{c}\text { Storage } \\
\text { Period } \\
\text { (days) }\end{array}$} & \multicolumn{2}{|c|}{ PSC $_{\mathbf{0 . 5}}$} & \multicolumn{2}{c|}{ PSC $_{\mathbf{0 . 7 5}}$} & \multicolumn{2}{c|}{ PSC $_{\mathbf{1 . 0}}$} \\
\cline { 2 - 7 } & PET JAR & GLASS JAR & PET JAR & GLASS JAR & PET JAR & GLASS JAR \\
\hline Fresh & $0.050 \pm .012$ & $0.050 \pm .008$ & $0.049 \pm .021$ & $0.049 \pm .004$ & $0.047 \pm .0012$ & $0.047 \pm .012$ \\
\hline 15 & $0.052 \pm .020$ & $0.052 \pm .008$ & $0.050 \pm .004$ & $0.051 \pm .004$ & $0.048 \pm .012$ & $0.048 \pm .016$ \\
\hline 30 & $0.054 \pm .014$ & $0.056 \pm .021$ & $0.052 \pm .016$ & $0.053 \pm .024$ & $0.050 \pm .020$ & $0.051 \pm .028$ \\
\hline 45 & $0.056 \pm .028$ & $0.059 \pm .017$ & $0.054 \pm .021$ & $0.056 \pm .024$ & $0.052 \pm .020$ & $0.054 \pm .031$ \\
\hline 60 & $0.059 \pm .018$ & $0.063 \pm .008$ & $0.057 \pm .012$ & $0.060 \pm .016$ & $0.055 \pm .021$ & $0.058 \pm .028$ \\
\hline 75 & $0.061 \pm .024$ & $0.065 \pm .016$ & $0.059 \pm .032$ & $0.062 \pm .013$ & $0.057 \pm .011$ & $0.060 \pm .019$ \\
\hline 90 & $0.064 \pm .019$ & $0.069 \pm .024$ & $0.062 \pm .021$ & $0.065 \pm .027$ & $0.061 \pm .028$ & $0.063 \pm .017$ \\
\hline
\end{tabular}

Table 5: Changes in Vitamin-C content $(\mathrm{mg} / \mathbf{1 0 0 g})$ of papaya leather during storage as affected by levels of citric acid and packaging materials

\begin{tabular}{|c|c|c|c|c|c|c|}
\hline \multirow{2}{*}{$\begin{array}{c}\text { Storage } \\
\text { Period } \\
\text { (days) }\end{array}$} & \multicolumn{2}{|c|}{ PSC $_{\mathbf{0 . 5}}$} & \multicolumn{2}{c|}{ PSC $_{\mathbf{0 . 7 5}}$} & \multicolumn{2}{c|}{ PSC $_{\mathbf{1 . 0}}$} \\
\cline { 2 - 7 } & PET JAR & GLASS JAR & PET JAR & GLASS JAR & PET JAR & GLASS JAR \\
\hline Fresh & $58.75 \pm .079$ & $58.75 \pm .085$ & $57.30 \pm .074$ & $57.30 \pm .065$ & $56.40 \pm .072$ & $56.40 \pm .077$ \\
\hline 15 & $57.55 \pm .068$ & $57.65 \pm .077$ & $56.15 \pm .072$ & $56.25 \pm .073$ & $55.25 \pm .062$ & $55.40 \pm .028$ \\
\hline 30 & $56.40 \pm .028$ & $56.45 \pm .019$ & $55.05 \pm .018$ & $55.10 \pm .012$ & $54.20 \pm .024$ & $54.35 \pm .020$ \\
\hline 45 & $54.85 \pm .021$ & $55.25 \pm .029$ & $53.80 \pm .016$ & $54.00 \pm .020$ & $53.05 \pm .036$ & $53.80 \pm .028$ \\
\hline 60 & $53.35 \pm .019$ & $54.05 \pm .024$ & $52.45 \pm .036$ & $52.90 \pm .018$ & $52.80 \pm .025$ & $51.80 \pm .032$ \\
\hline 75 & $51.45 \pm .016$ & $53.80 \pm .038$ & $51.20 \pm .028$ & $51.40 \pm .031$ & $51.00 \pm .017$ & $50.95 \pm .024$ \\
\hline 90 & $50.35 \pm .029$ & $51.40 \pm .032$ & $49.20 \pm .022$ & $50.20 \pm .018$ & $48.85 \pm .016$ & $49.05 \pm .026$ \\
\hline
\end{tabular}

Table 6: Change in overall acceptability of papaya leather as affected by citric acid levels and packaging materials of fresh and stored papaya leather

\begin{tabular}{|l|l|l|l|l|l|l|}
\hline \multirow{2}{*}{$\begin{array}{l}\text { Storage } \\
\begin{array}{l}\text { Period } \\
\text { (days) }\end{array}\end{array}$} & \multicolumn{2}{|c|}{ PSC $_{\mathbf{0 . 5}}$} & \multicolumn{2}{c|}{ PSC $_{\mathbf{0 . 7 5}}$} & \multicolumn{2}{c|}{ PSC $_{\mathbf{1 . 0}}$} \\
\cline { 2 - 7 } & PET JAR & GLASS JAR & PET JAR & GLASS JAR & PET JAR & GLASS JAR \\
\hline Fresh & $7.352 \pm .14$ & $7.352 \pm .14$ & $7.585 \pm .25$ & $7.585 \pm .25$ & $7.282 \pm .165$ & $7.282 \pm .165$ \\
\hline 30 days & $7.31 \pm .012$ & $7.335 \pm .004$ & $7.492 \pm .016$ & $7.535 \pm .032$ & $7.26 \pm .073$ & $7.28 \pm .015$ \\
\hline 60 days & $7.287 \pm .032$ & $7.312 \pm .020$ & $7.462 \pm .070$ & $7.512 \pm .042$ & $7.222 \pm .014$ & $7.225 \pm .016$ \\
\hline 90 days & $7.222 \pm .030$ & $7.277 \pm .045$ & $7.415 \pm .012$ & $7.457 \pm .032$ & $7.162 \pm .024$ & $7.21 \pm .018$ \\
\hline
\end{tabular}

